attending to this phase of the question. He hopes to introduce gutta-percha bedding, which will be regularly washed with an antiseptic solution, and to insist on a bath as an indispensable preliminary. To wash a dirty man is to save society from one of the dangers that menace public health; and it is a hopeful sign when we note that these principles are gaining ground even in the slums of Paris.

Speaking of Dr. Passant, I ought to say that he is the founder of the Medical Night Service which has been adopted in Brussels, St. Petersburg, Paris, and within the last month or so in the town of Algiers. Experience has shown that in towns visited by a great many foreigners, doctors are liable to be disturbed in the night by strangers who as often as not fail to pay the fees. Hence a great many medical men refuse to go to visit strangers in the night, and these latter are often perplexed to obtain the assistance they require. Dr. Passant, therefore, suggested that a medical man should be attached to each police-station. Thus in Paris and the other towns mentioned a stranger not known to any doctor should at once apply to the nearest police-station. A policeman will immediately fetch the doctor attached to the service, and accompany him from his house to that of the patient and back again home, thus protecting him from the thieves, who often call a doctor out during the night for the express purpose of robbing him. The fee is fixed at ten francs, and if the patient is too poor to pay this, the policeman who is there to witness the circumstance gives the doctor a ticket for the amount, which is immediately cashed on presentation at the Prefecture of Police. Thus the stranger can always count on prompt and competent medical attendance; while, on the other hand, the doctor is certain not to be disturbed in vain, he is protected and has his fee secured by the administration.

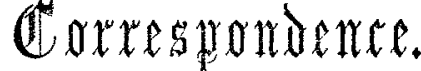

"Audi alteram partem."

\section{ANTISEPTIC SURGERY IN LARGE HOSPITALS.}

To the Editor of THE LANCET.

SIR,-Amid the multitude of statistics $I$ have as yet seen none that would point out a striking diminution of mortality in large hospitals where the older plans of treating operationcases have become replaced by the strict antiseptic method of Lister. Now, in the Newcastle-on-Tyne Infirmary, where major amputations are numerous, we have a good basis for statistical comparison, for during the last three years Lister's method has been invariably and rigorously carried out, whereas in the preceding three years the "carbolic oil" and other simple methods were employed. Arranging the details of these years systematically, we have :-

\begin{tabular}{ccccc} 
Year. & \multicolumn{3}{c}{ Major amputations. } & Deaths. \\
1873 & $\ldots$ & 27 & $\ldots$ & 16 (or $59 \cdot 2$ per cent.) \\
1874 & $\ldots$ & 41 & $\ldots$ & 19 (or 46.3 per cent.) \\
1875 & $\ldots$ & 30 & $\ldots$ & 14 (or 46.6 per cent.)
\end{tabular}

Antiseptic years.

$\begin{array}{lllll}1876 & \ldots & 26 & \ldots & 6 \text { (or } 23 \text { per cent.) } \\ 1877 & \ldots & 32 & \ldots & 5 \text { (or 15.6 per cent.) } \\ 1878 & \ldots & 50 & \ldots & 2 \text { (or } 4 \text { per cent.) }\end{array}$

Taking the total of each period of three years, we have formerly 98 amputations, with 49 (or 50 per cent.) deaths; latterly 108 amputations, with 13 (or 12 per cent.) deaths.

Moreover, in the former period there were 8 double amputations, with 5 deaths; in the latter, 4 of these, with no deaths.

The results of the last year would call for more special comment, for the 3 double amputations and the 13 amputations of the thigh ( 8 of them primary) were all successful; while the only 2 deaths from the total 50 major amputations followed amputation at the hip-joint for injury. I may add that of 6 cases of ovariotomy, 4 recovered. Even making due allowance for other important sanitary improvements of recent years, I cannot but think that the statistics here recorded will sufficiently point out the great security ensured by the adoption of Lister's method in large hospitals, where major operations are frequently performed, and the wards are teeming with grave surgical cases.

I am, Sir, your obedient servant,

$$
\text { L. J. HobsoN, M.B., F.R.C.S., }
$$

Newcastle-on-Tyne Infirmary, May 30th, 1878.

** Surgeons and patients at the Newcastle-on-Tyne Infirmary are to be congratulated on the low mortality during the last three years as compared with the enormous excess of the three previous years. A mortality of 50 per cent. is appalling, and whatever may be the representative value of 12 per cent. for the antiseptic system, no one would pretend that 50 per cent. is a fair average of the mortality under the best non-antiseptic methods. - ED. L.

\section{HYDATID IN THE FEMALE BREAST.}

\section{To the Editor of THE LANCET.}

SIR,-The extreme rarity of cases of "hydatid" in the female breast must be my excuse for asking you to put on record the following case.

Mrs. S-, the mother of five children, came to consult me in March, 1878, for a tumour of the left breast, which she had been troubled with for the last six years. When she first noticed it, it was about the size of a pea, and could be moved about under the skin. It gradually increased in size, and during the latter part of the six years she suffered slightly from shooting pains in the breast, which extended up into the left armpit. The pain was not worse at night, and there was no glandular swelling in the axilla or history of tumour in the family. She was living far up in the north of the continent, and so had put off getting medical advice, especially as the pain was never very severe. Some time before, I had her servant under my care with five or six "hydatid" tumours of the liver, from which she died, and this inclined me to make the diagnosis of "hydatid"; but as several other medical men thought it was "fibro-cystic," and as the patient would have nothing done without ether, I determined to remove it. This was done by an incision about four inches in length, and the "hydatid" cyst was found to be about the size of a goose's egg, containing about six or seven small daughter-vesicles. The base of the tumour was situated in the pectoralis major muscle, from which it was carefully dissected and removed entire with a small portion of the surronnding fat. The wound was sponged out with chloride of zinc (30 grains to the ounce), and healed by "first intention."

William Gardner, M.D., Ch.M. Glas. Late Senior House-surgeon, Adelaide Hospital.

Adelaide, South Australia, April 17th, 1878.

\section{DISCHARGE OF A LARGE BILIARY CALCULUS BY ULCERATION THROUGH THE ABDOMINAL PARIETES.}

To the Editor of THE LANCET.

Srr,-Mr. Cookson, of Halifax, and Mr. Yeldham, of London, having reported, on January 5th and 19th, an instance of a case in which biliary calculi escaped by ulceration through the abdominal walls, I beg to send you the notes of a case which has been under my care.

Mrs. E_, aged seventy-four, reciding at Langford, Essex, had, ten years ago, three attacks of severe pain, followed by jaundice. After the last attack she passed several gall-stones about the size of small peas. She remained in good health until August, 1877, when she consulted me, and on visiting her, $I$ found in the right hypochondriac and epigastric regions a very hard swelling six inches in diameter, from which she was suffering acute pain. An abscess formed, which burst on Nov. 13th, and a large quantity of offensive pus came away. On Dec. 28th a large oval calculus passed through the opening.

The patient's health now rapidly improved, her appetite became good, and the pain mitigated. There was considerable swelling and induration. A probe could be passed three and a half inches into the opening, which assumed the character of a fistula discharging serous fluid.

She continued in this state upwards of three months, when 
she was taken with pain followed by jaundice and considerable hæmorrhage from the opening. She died April 28th.

The calculus weighs 170 grains, and measures $3 \frac{5}{8}$ inches in the long and 3 inches in the short circumference. I am, Sir, yours truly,

Edwin Parker Gutteridge, M.R.C.S. Eng. Maldon, Essex, May, 1878.

\section{SECTION-CUTTING BY MEANS OF ETHER SPRAY. \\ To the Editor of THE LANCET.}

SIR,-In THE LANCET of April 27th an article appeared directing the attention of pathologists \&c. to a new method of section-cutting by means of ether spray. Now, this precise method of using the spray for microscopic purposes was previously mentioned in your journal (Feb. 19th, 1876) more than two years before, and in a paper in which ether spray was for the first time recommended to microscopists. The so-called new method was consequently the very first of those adopted for the purpose, and the apparatus, of which a woodcut was published, was the same as that now advised by Dr. Smith. I have no doubt he was not aware of this, but a moment's comparison of the two papers will convince him of the fact.

I myself now use a different, and, I think, a better apparatus on the same principle.

\section{I am, Sir, yours faithfully,}

ChARLES COPPINGER

May 30th, 1878 .

Surgeon to the Mater Misericordiæ Hospital, Dublin.

\section{PARLIAMENTARY PROCEEDINGS.}

\section{HOUSE OF LORDS.}

Tuesday, June 4 th.

MEDICAL ACT (1858) AMENDMENT.

THEIR Lordships having gone into Committee on this Bill Clauses 1 and 9 were agreed to. Clause 3 was also agreed to after some verbal amendments introduced by the Marquis of Pipon. On Clause 4, which would have made it necessary for a person who had passed the joint board examination to obtain a merical diploma from one of the existing medical authorities before he could be placed on the Medical Register, the Marquis of Ripon moved an amendment to make such diploma unnecessary for the purposes of registration. The Duke of Richmond and Gordon approved the amendment. The amendment was agreed to, and Clause 4 as amended, and the remaining clauses, after verbal amendments, were ordered to stand part of the Bill. The Bill was then passed through Committee and reported to the House.

\section{(B) bituan'y.}

\section{DR. KOVACS-SEBESTENY ENDRE.}

AN eminent member of the profession has just passed away very suddenly at Budapest, in Hungary. The accounts we receive of the expression of universal sympathy with the family of the deceased, and of the respect shown by crowds of rich and poor who followed his remains to the grave, testify to the worth of the man while he lived and to the just appreciation of the services which our profession is capable of rendering to suffering humanity in any country.

Dr. Kovács was for years past the leading medical authority in Budapest. Apparently in usual health, he was attending to his patients, and whilst prescribing for one of them who had just sent for him, Dr. Kovács complained of a sudden pain in the head. He fell, and died almost instantly. The autopsy revealed an unsuspected aneurism of the aorta, the bursting of which carried him off, at the age of sixtythree.

Dr. Kovács was the son of a Protestant clergyman, and received his medical education at the University of Budapest. At first an assistant to the celebrated surgeon, Balassa, he soon obtained an extensive practice, and became a well- known name in the Hungarian medical and scientific literature. Subsequently he became the intimate friend and professional adviser of the great Hungarian patriot, Deák, and the Sovereign repeatedly bestowed royal favours on Dr. Kovács. He was buried on the 20th of May, followed by thousands to the grave.

Among the many wreaths put on his coffin was one with the inscription, "From the Government of Hungary," placed there by the Ministers of State, three of whom took part in the funeral procession. There were also present the Presidents of both Houses of Parliament, numerous members of the aristocracy and of the Academy of Sciences, \&c.

\section{attedical afléps.}

APOTHECARIES' HALL. - The following gentlemen passed their examination in the Science and Practice of Medicine, and received certificates to practise, on May 30th:Alden, Ebenezer Wenham, Oxford. Castle, Hutton, Newport, Isle of Wight. Homes, James, Ledbury.

Hughes, Thomas Montgomery, Kennington-road. Lighton, H. Alfred Hamilton, Ross. Lynn, Edward, Woolwich, Kent. Michael, Henry James, Colchester. Watson, Evan John, Durham.

The following gentlemen also passed the Primary Pro. fessional Examination:-

Henry Louis Preston Hardy and Arthur Llnyd Jones, London Hospital ; Alfred Cox Wey, Middlesex Hospital.

[In the Primary Examination list published on March 16th, for "St. Mary's Hospital," following the name Frederick Enos Fenton, substitute "St. George's Hospital."]

Robert Smith, L.R.C.P. Edin., of Fochabers, has been placed on the Commission of the Peace for the county of Elgin.

DR. CoATEs, of Portumna, has received a severe fracture of the hip by being thrown from a croydon, caused by his horse becoming restive and bolting.

Mr. William EDDowes, late medical officer for the Pontesbury district of the Atcham Union, has obtained a superannuation allowance of $£ 50$ per annum.

Royal College of Surgeons of England. Professor T. Spencer Wells will commence his course of six lectures "On the Diagnosis and Surgical Treatment of Abdominal Tumours," on Monday next, at 4 o'clock P.M. The final examination for the Fellowship of the College terminated on Monday last; of the twenty-two candidates who entered for it seventeen were successful.

Convalescent Hospital, Blackrock.-The late Mr. Mullins, of Dublin, who died about six years since, having left a large sum of money for charitable purposes, a Convalescent Hospital has been recently finished at Black. rock, near Dublin, and is now ready for the reception of patients from certain of the city hospitals. By the testator's will a large sum is available for its permanent endowment.

Royal College of Surgeons IN IRELand. The following office-bearers were elected on the 3rd instant for the ensuing year :-President: Philip Crampton Smyly. Vice-President: Edward D. Mapother. Secretary: William Colles. Council : John K. Barton, Samuel Chaplin, William Colles, Henry Gray Croly, Anthony H. Corley, John Denham, William A. Elliott, Edward Hamilton, Archibald H. Jacob, George H. Kidd, Edward Ledwich, Rawdon Macnamara, Alfred H. MeClintock, Robert McDonnell, Benjamin F. McDowell, Benjamin G. McDowel, George H. Porter, William Stokes, T. Jolliffe Tufnell.

Presentations.-Dr. Robert Morton has been presented with an address and 200 guineas on leaving Castleblaney, county Monaghan.-Dr. Joshua R. Harvey has been presented, on the occasion of his retirement from practice, with an illuminated address in gilt frame, and a silver tea-kettle.-Mr. John Todd has been presented with a handsome clock and side ornaments, principally by the sub. scriptions of the poorer classes, to testify their appreciation of his kindness to them during the time he was resident medical officer to the Lancaster Infirmary and Dispensary, and especially during the scarlet fever and small-pox epidemics. 